\title{
Architectural changes in larval leaf shelters of Noctuana haematospila (Lepidoptera: Hesperiidae) between host plant species with different leaf thicknesses
}

\author{
Harold F. Greeney ${ }^{1,3}$; Thomas R. Walla ${ }^{2} \&$ Ryan L. Lynch ${ }^{1}$
}

\author{
1 Yanayacu Biological Station and Center for Creative Studies, Cosanga, Ecuador \\ c/o 721 Foch y Amazonas, Quito, Ecuador. E-mail: revmmoss@yahoo.com \\ ${ }^{2}$ Department of Biology, Mesa State College, 1100 North Avenue, Grand Junction, CO 81501. E-mail: twalla@mesastate.edu \\ ${ }^{3}$ Corresponding Author.
}

\begin{abstract}
Insect-food-plant associations have been shown to be influenced by the chemical, physical and nutritional characteristics of plants. We suggest that among insect larvae that use leaf material to build shelters, food-plant use may be constrained by differences in host leaf structure, illuminating a rarely investigated aspect of insect-plant interactions. To explore the potential effects of leaf structure on shelter building behavior in a Neotropical skipper butterfly, we investigated shelter building patterns on two congeneric food-plants that varied in leaf thickness. Shelter architecture varied significantly between hosts, with thicker leaves requiring longer cuts to construct shelters. The relationship between shelter building behavior and leaf structure is discussed in relation to selection pressures on larval shelters and food-plant choice.
\end{abstract}

KEY WORDS. Behavior; caterpillar; Ecuador; Rubus; skipper.

Lepidopteran larvae of at least 18 families construct and occupy shelters or refugia built on or near their food-plant (e.g. DeVries 1987, 1997, Stehr 1987, Scoble 1992, Greeney 2009). The architecture and complexity of shelters varies among species, but often involves a precisely executed series of cuts and folds, performed by larvae multiple times throughout their development (e.g. Greeney \& Jones 2003, Weiss et al. 2003). This sophisticated and time-consuming behavior has inspired authors to suggest a variety of important roles that shelters may play in larval life history, the most popular being protection from predation (e.g. Loeffler 1996, Eubanks et al. 1997, Jones et al. 2002). Larval shelter-building behavior can secondarily affect other herbivore-food-plant interactions such as phytochemistry (Sandberg \& Berenbaum 1989, Sagers 1992) and may also influence entire arthropod communities by increasing overall arthropod diversity on food-plants (LILL \& MARQUIS 2003, 2004). As such, larval shelter construction may yield insight into the ecology and evolution of both insect-food-plant interactions as well as community structure. Of particular interest is the question of whether leaf properties such as thickness or texture may affect the architecture of larval shelters, affecting larval fitness on different food-plants and influencing lepidopterafood-plant coevolution.

Skipper butterflies (Hesperiidae) construct shelters throughout larval development and show a large amount of interspecific and ontogenetic variation which may be phylo- genetically informative within this group (GREENEY \& Jones 2003, Greeney 2009). While shelter building is widespread among Neotropical skipper larvae (e.g. Moss 1949, Young 1985, Burns $\&$ JANZEN 2001), the details of shelter architecture are available for only a few species (e.g. Greeney \& Warren 2003, 2004, 2009, Weiss et al. 2003, Greeney \& Young 2006).

Fifteen years of observations on the shelter building behavior of skipper larvae throughout the Americas suggests that, while final shelter structure is conserved, the details of architecture may vary, even within a species utilizing multiple hosts. We tested this observation by quantifying variation in shelter architecture of first and second larval stadia of a skipper butterfly which feeds on two species of food-plants that differ in leaf thickness.

\section{MATERIAL AND METHODS}

Noctuana haematospila (C. Felder \& R. Felder, 1867) is a skipper butterfly with well described larval shelters (GreEney \& WARREN 2004), and is distributed from Venezuela to Bolivia in the northern Andes above 1000 m (Evans 1953). Eggs of $N$. haematospila are laid singly on the dorsal surface of Rubus spp. (Rosaceae) host plants. Larvae of all instars construct and occupy shelters on leaves where eggs are laid. Typically, 3-4 shelters are built during larval ontogeny; the first shelter is constructed upon emergence from the egg, and larger subsequent shelters are made as larvae grow, with the second shelter typi- 
cally built by late second or early third instars. The first and second larval shelters, termed "Type 3, center-cut shelters" by GreENEY (2009) are round or oval sections of leaf, excised and flipped over onto the dorsal surface of the leaf, folded across a narrow bridge or hinge (Fig. 1). To create such a shelter, a single, circular cut is made in the leaf which curves around to nearly join with its point of origin, leaving an uncut bridge where the shelter folds. Thus, a shorter bridge represents more cutting by the larva. This provides the larvae with a small man-hole-like cover, under which it lives (GREeney \& WARREN 2004). Terminology for describing shelter architecture follows GreENEY \& JoNES (2003) and Greeney (2009).



Figure 1. Photograph of first larval shelter of Noctuana haematospila in eastern Ecuador. Lines indicate the dimensions recorded for both first and second larval shelters: a) length of shelter lid parallel to the shelter bridge, b) width of the shelter bridge perpendicular to prior measurement, c) bridge width.

We made all observations at the Yanayacu Biological Station and Center for Creative Studies ( $2100 \mathrm{~m}$ a.s.l.) in the Quijos Valley of Ecuador's NE Napo Province, five kilometers west of the town of Cosanga. Yanayacu Biological Station shares a 2000 ha reserve with Cabañas San Isidro and is bordered by thousands of hectares of primary forest with scattered agricultural communities. For more complete descriptions of habitat in the area, see Greeney et al. (2006) and Valencia (1995).

Of the four species of Rubus Linnaeus, 1753 known to occur at the study site, $R$. urticifolius Poiret, 1804 and $R$. boliviensis Focke, 1874 were dominant in preliminary surveys and were the most frequent hosts of $N$. haematospila (GREENEY \& WARREN 2004, GreEney pers. obs.). To assess the relative use of these two Rubus spp., we exhaustively searched for early instar shelters of $N$. haematospila, empty and occupied, on all individuals of $R$. urticifolius and $R$. boliviensis at the forest edge along the 5-km road from Yanayacu to Cosanga. Because first instar shelters are more reliably encountered than eggs, we used the presence of first larval shelters to indicate an oviposition event. We collected all leaves encountered with first and second shelters, and made three measures of shelter architecture (Fig. 1) on flattened leaves in the lab using a digital caliper with $0.01 \mathrm{~mm}$ precision. To assess the relative thickness of leaves of the two focal Rubus spp., we used the same calipers to measure the thickness of 10 fully expanded leaflets from each of 10 plants in the field. We avoided large secondary veins, compressing the caliper arms by hand to measure the thickest portion of the leaf between secondary veins near the leaf edge.

We assessed differences in shelter architecture between food-plant species using t-tests for differences in the mean of each of these three quantified shelter dimensions. We measured patterns of food-plant usage using a Chi-square test for homogeneity of first instar shelter frequency on plant species and a t-test for difference in the mean number of shelters observed on each plant. We compared mean leaf thickness of the two food-plants using a two-tailed t-test after pooling the 100 samples from each plant species.

\section{RESULTS}

We surveyed $114 R$. urticifolius and 87 R. boliviensis plants along the road, yielding 149 first instar $N$. haematospila shelters and 86 second shelters. Statistical tests for homogeneity of caterpillar frequency on host plant species based on the average number of first instar shelters per plant within species $(t-$ test result $\mathrm{p}<0.001)$ and the number of plants with first shelters $\left(\chi^{2}=9.736, \mathrm{df}=1, \mathrm{p}<0.001\right)$ showed $R$. boliviensis was used significantly more often than $R$. urticifolia. Mean leaf thickness ( $\pm \mathrm{SD})$ of $R$. boliviensis $(0.19 \pm 0.03 \mathrm{~mm})$ was significantly less than that of $R$. urticifolia $(0.26 \pm 0.04 \mathrm{~mm})$ (two-tailed $\mathrm{t}$ test, $\mathrm{p}>0.001$ ). Dimensions of the excised shelter "lid" (length by width) and the width of the "bridge" where the shelters hinge are presented in table I. While the dimensions of shelter lids were equivalent between food-plant species for first and second shelters, the width of the bridge was significantly larger in first shelters for larvae on $R$. boliviensis (two-tailed t-test, $\mathrm{p}<$ 0.001), indicating that larvae spent less time (ie., less cutting) when building first shelters on the thinner-leafed food-plant. Second shelters showed no significant differences (two-tailed t-test, $\mathrm{p}=0.144$ ) in the width of the bridge between the two hosts, suggesting that larger larvae were less constrained by leaf thickness. 
Table I. Measurements of first and second larval shelters of N. haematospila, mean, and standard deviation for each of the three measurements of shelter architecture for first two shelters built by larvae. The size of excised leaf material is constant across both host plant species. Width of the bridge where the leaf is folded is significantly greater in shelters built on $R$. boliviensis indicating less cutting was required by larvae on this species.

\begin{tabular}{cccccc}
\hline & Foodplant species & $\mathrm{N}$ & Mean shelter width mm (s.d) & Mean shelter length mm (s.d.) & Mean bridge width mm (s.d.) \\
\hline Shelter 1 & R. urticifolia & 51 & $4.029(0.384)$ & $4.396(0.448)$ & $1.841(0.442)^{*}$ \\
& R. boliviensis & 98 & $4.139(0.422)$ & $4.459(0.417)$ & $2.109(0.390)^{*}$ \\
\multirow{3}{*}{ Shelter 2 } & R. urticifolia & 27 & $8.632(1.153)$ & $8.703(1.068)$ & $3.730(0.989)$ \\
& R. boliviensis & 59 & $8.451(1.605)$ & $8.810(1.478)$ & $4.068(0.962)$ \\
\hline
\end{tabular}

\section{DISCUSSION}

In an attempt to understand the forces driving food-plant selection and herbivore-food-plant coevolution, biologists have explored a wide variety of physiological, chemical, and evolutionary interactions between many different herbivore-plant taxa (e.g. Ehrlich \& Raven 1965, Gilbert 1971, Woodman \& Fernandes 1991, Dyer et al. 2001, ZALUCKI et al. 2001). Plant architecture and leaf morphology, though they have received little attention (MARQUIS 1992), may directly affect the abundance of certain herbivores (HAYsom \& Coulson 1998, MARQuIs et al. 2002), as well as intraspecific variation in food-plant use (Alonso \& Herrera 1996) and larval survival (LoEfFler 1993). MARQUIs et al. (2002) showed that the spatial arrangement of oak leaves had an important effect on the abundance of shelter building larvae, and suggested that increasing distances between adjacent leaves prevented tiny first stadia larvae from tying leaves together. In our investigation of the influence of leaf thickness on shelter architecture, we found N. haematospila shelters built by first instars showed significant architectural changes correlated with leaf thickness, but those built by second or third instars showed relatively little change. Thus, like the study of MARQuis et al. (2002), we found that the challenges posed to larvae by leaf thickness were likely most important for early stadia skipper larvae.

As shelter building lepidopteran larvae harness the elastic properties of silk by super-stretching it, and repeatedly spinning numerous lines of silk to move portions of leaves into the desired position (Fitzgerald \& Clark 1994, Fitzgerald et al. 1991), it follows that more resistant manipulations will require more time and energy to perform. The bridge portion of the young larval shelters of $N$. haematospila is the hinge on which the shelter lid is folded over to meet the leaf surface. The width of this bridge will have a direct effect on the ease with which this fold may be accomplished: wider bridges will present more resistance to folding than shorter ones. Thus, a larva which cuts more of the leaf, leaving a narrower bridge, will meet with less resistance in folding over the leaf. We found significant differences in the relative width of this bridge between shelters built on two congeneric food-plant species varying in leaf thickness. We suspect this difference is correlated with greater resistance of thicker leaves to folding. As larval shelters may help to protect larvae from pre- dation and dislodgement (LOEFfler 1996, Eubanks et al. 1997, Jones et al. 2002), longer construction periods may increase exposure to predators (LoEfFler 1993). Selection, therefore, should favor modifications in shelter building behaviors which minimize this period of exposure. In fact, when comparing larval survivorship on two congeneric plants with varying leaf thickness, LOEFFLER (1993) found that shelter building moth larvae survived better on the thin-leafed host, and postulated that this was due to relative speed with which young larvae could fold thinner leaves, thus reducing their exposure to predators or dislodgement from the plant. Similarly, in the case of $N$. haematospila, host plant choice may affect the amount of labor and time needed to construct larval shelters (more vs. less cutting), and selection should favor females who lay eggs on host plants that allow shelters to be built with minimal exposure time.

We did not test female oviposition preference directly, but the distribution of first stadia larvae among Rubus species at our study site provides cautious support for greater oviposition frequency by $N$. haematospila on the plant species which requires less cutting by larvae. To this end, we found clear statistical evidence that more first stadia larvae were found on the thin-leaved Rubus species, a pattern which may reflect foodplant preference by ovipositing females, but we did not perform experiments to eliminate other explanations for oviposition patterns. We acknowledge that female host preference may be driven by one or more alternative factors including foodplant phytochemistry, apparency, or predation. Because our observations are consistent with a pattern expected if leaf thickness is important for larval survival, we offer them as an incentive for others to consider the potentially substantial influence of subtle aspects of leaf morphology on food-plant associations in shelter building species.

Shelter building in the Hesperiidae is thought to be a fairly conserved character (GreENEy \& Jones 2003, Greeney 2009), and a recent study comparing the micro-architecture of two hesperiids building architecturally similar shelters suggests that even minor modifications to the process of shelter construction may be phylogenetically informative (Greeney \& SHELDON 2008). Our data suggest that understanding the physical characteristics of foodplants, and how these affect shelter construction, may be crucial to understanding the evolution of different shelter types 
between lineages. The interaction between plant architecture and leaf morphology, and the construction of herbivore leaf shelters, may affect herbivore-host interactions in several important ways. First, shelter-building herbivores may be constrained by the type of shelter larvae are physically capable of constructing, thus necessitating a shift in shelter architecture before a successful shift in food-plant species can be made. Secondly, as shelter architecture may be affected by food-plant shifts within lineages, we might expect predictable changes in shelter architecture which coincide with ancestral shifts in food-plant species. We suggest that studies of variation in the architectural details of shelter construction, both between and within species feeding on different hosts, will provide additional insight into the evolution of larval shelter construction and food-plant use in shelter building Lepidoptera.

\section{ACKNOWLEDGEMENTS}

We thank Carmen Bustamante and Mitch Lysinger for their friendship and hospitality at Cabañas San Isidro. We thank Andrew Warren, Ryan Berger, Martha Weiss, and John Lill for helpful comments on earlier versions of this manuscript. This study was funded in part by NSF grant \#DEB-0346729, as well as by the donations of Matt Kaplan and John Moore through the Population Biology Foundation. As always our natural history interests were supported and nurtured by the PBNHS. This is publication number 139 of the Yanayacu Natural History Research Group and is dedicated to George Austin.

\section{LITERATURE CITED}

Alonso, C. \& C.M. Herrera. 1996. Variation in herbivory within and among plants of Daphne laureola (Thymelaeaceae):correlation with plant size and architecture. Journal of Ecology 84: 495-502.

Burns, J.M. \& D.H. Janzen. 2001. Biodiversity of Pyrrhopygine skipper butterflies (Hesperiidae) in the Area de Conservación Guanacaste, Costa Rica. Journal of the Lepidopterists' Society 55: 15-43.

DeVries, P.J. 1987. The butterflies of Costa Rica and their natural history. Princeton, Princeton University Press, vol. 1, $327 \mathrm{p}$.

DeVries, P.J. 1997. The butterflies of Costa Rica, Vol. 2, Riodinidae. Princeton, Princeton University Press, 288p.

Dyer, L.A.; C.D. Dodson; J. Beihoffer \& D.K. Letourneau. 2001. Trade-offs in anti-herbivore defenses in Piper cenocladum: ant mutualists versus plant secondary metabolites. Journal of Chemical Ecology 27: 581-592.

Ehrlich, P.R. \& P.H. Raven. 1965. Butterflies and plants: a study in coevolution. Evolution 18: 586-608.

Eubanks, M.D.; K.A. Nesci; M.K. Peterson; Z. Liu \& H.B. Sanchez. 1997. The exploitation of an ant-defended host plant by a shelter building herbivore. Oecologia 109: 454-460.

Evans, W.H. 1953. A catalogue of the American Hesperiidae indicating the classification and nomenclature adopted by the British Museum (Natural History). Part 3 (groups E, F, G), Pyrginae, section 2. London, British Museum, 246p.

Fitzgerald, T.D. \& K.L. Clark. 1994. Analysis of leaf-rolling behavior of Caloptilia serotinella (Lepidoptera: Gracillariidae). Journal of Insect Behavior 7: 859-872.

Fitzgerald, T.D.; K.L. Clark; R. Vanderpool \& C. Phillips. 1991. Leaf shelter-building caterpillars harness forces generated by axial retraction of stretched and wetted silk. Journal of Insect Behavior 4: 21-32.

Gilbert, L.E. 1971. Butterfly-plant coevolution: has Passiflora adenopoda won the selectional race with heliconiine butterflies? Science 172: 585-586.

Greeney, H.F. 2009. A revised classification scheme for larval hesperiid shelters, with comments on shelter diversity in the Pyrginae. Journal of Research on the Lepidoptera 41: 53-59.

Greeney, H.R. \& M. Jones. 2003. Shelter building in the Hesperiidae: a classification scheme for larval shelters. Journal of Research on the Lepidoptera 37: 27-36.

Greeney, H.F. \& K.S. Sheldon. 2008. Comments on the larval shelter construction and natural history of Urbanus proteus Linn., 1758 (Hesperiidae: Pyrginae) in southern Florida. Journal of the Lepidopterists' Society 62: 1008-1010.

Greeney, H.F. \& A.D. WARren. 2003. Notes on the natural history of Eantis thraso (Hesperiidae: Pyrginae) in Ecuador. Journal of the Lepidopterists' Society 57: 43-46.

Greeney, H.F. \& A.D. Warren. 2004. The life history of Noctuana haematospila (Hesperiidae: Pyrginae) in Ecuador. Journal of the Lepidopterists' Society 59: 6-9.

Greeney, H.F. \& A.D. Warren. 2009. The natural history and shelter building behavior of Falga jeconia ombra Evans, 1955 in eastern Ecuador (Lepidoptera, Hesperiidae, Hesperiinae). Journal of Insect Science 9: 33.

Greeney, H.F. \& J.J. Young. 2006. Observations on the shelter building behavior of some Asian skipper larvae (Lepidoptera: Hesperiidae). Journal of Research on the Lepidoptera 39: 86-89.

Greeney, H.F; R.C. Dobbs; G.I.C. Diaz; S. Kerr \& J.G. Hayhurst. 2006. Breeding biology of the Green-fronted Lancebill (Doryfera ludovicae) in eastern Ecuador. Ornitologia Neotropical 17: 321-331.

HaYsom, K.A. \& J.C. Coulson. 1998. The Lepidoptera fauna associated with Calluna vulgaris: effects of plant architecture on abundance and diversity. Ecological Entomology 23: 377-385.

Jones, M.T.; I. Castellanos \& M.R. Weiss. 2002. Do leaf shelters always protect caterpillars from invertebrate predators? Ecological Entomology 27: 753-757.

Lill, J.T. \& R.J. Marquis. 2003. Ecosystem engineering by caterpillars increases insect herbivore diversity on white oak. Ecology 84: 682-690.

LiLl, J. T. \& R. J. Marquis. 2004. Leaf ties as colonization sites for forest arthropods: an experimental study. Ecological Entomology 29: 300-308. 
Loeffler, C.C. 1993. Host plant and habitat effects on behavior, survival, and growth of early instar Dichomeris leuconotella (Lepidoptera: Gelechiidae), leaf-folders on goldenrods. Journal of Research on the Lepidoptera 32: 53-74.

Loeffler, C.C. 1996. Caterpillar leaf folding as a defense against predation and dislodgement: staged encounters using Dichomeris (Gelechiidae) larvae on goldenrods. Journal of the Lepidopterists' Society 50: 245-260.

MARQuis R.J. 1992. Selective impact of herbivores, p. 301-325. In: R.S. Fritz \& R.L. Simms (Eds). Plant resistance to herbivores and pathogens, ecology, evolution and genetics. Chicago, University of Chicago Press, 600p.

Marquis, R.J.; J.T. Lill \& A. Piccinni. 2002. Effect of plant architecture on colonization and damage by leaf tying caterpillars of Quercus alba. Oikos 99: 531-537.

Moss, A.M. 1949. Biological notes on some Hesperiidae of Pará and the Amazon. Acta Zoologica Lilloana 7: 27-79.

SAGERS, C.L. 1992. Manipulation of host plant quality: herbivores keep leaves in the dark. Functional Ecology 6: 741-743.

SAndberG, S.L. \& M.R. Berenbaum. 1989. Leaf tying by tortricid larvae as an adaptation for feeding on phototoxic Hypericum perforatum. Journal of Chemical Ecology 15: 875-885.

Scoble, M.J. 1992. The Lepidoptera. Form, function, and diversity. Oxford, Oxford University Press, 404 p.

Stehr, F. W. 1987. Immature insects. Dubuque, Kendall/Hunt Publishing Company, vol. 1, 754p.

VALENCIA, R.R. 1995. Composition and structure of an Andean forest fragment in eastern Ecuador, p. 239-249. In: S. Churchill; H. Balslev; E. Forero \& J.L. Luteyen (Eds). Biodiversity and conservation of Neotropical montane forests. New York, New York Botanical Garden, 702p.

Weiss, M.R.; E.M. Lind; M.T. Jones; D.J. Long \& J.L. MAupin. 2003. Uniformity of leaf shelter construction by larvae of Epargyreus clarus (Hesperiidae), the Silver-spotted Skipper. Journal of Insect Behavior 16: 465-480.

Woodman, R.L. \& G.W. Fernandes. 1991. Differential mechanical defense: herbivory, evapotranspiration, and leaf hairs. Oikos 60: 11-19.

Young, A.M. 1985. Natural history notes on Astraptes and Urbanus (Hesperiidae) in Costa Rica. Journal of the Lepidopterists' Society 39: 215-223.

Zalucki, M.P.; L.P. Brower \& A.M. Alonso. 2001. Detrimental effects of latex and cardiac glycosides on survival and growth of first-instar monarch butterfly larvae Danaus plexippus feeding on the sandhill milkweed Asclepias humistrata. Ecological Entomology 26: 212-224.

Submitted: 05.VII.2009; Accepted: 27.I.2010.

Editorial responsibility: Pedro Gnaspini 